\title{
Faculty Salaries and Alternative Forms of Representation
}

\author{
Felice Martinello \\ Department of Economics \\ Brock University, St Catharines, Ontario, L2S 3A1 \\ fmartinello@brocku.ca
}

February 2007

I would like to thank Larry Dufay from CAUT for providing the faculty salary data and supporting documentation, Donna Gray from OCUFA for help with the faculty collective bargaining and special plan data and Grant Amyot and Allan Heinicke for their help with the Queen's and Western (respectively) bargaining arrangements. I would also like to thank Karen Bentham, Susan Johnson, Steven Renzetti, and the participants of a University of Toronto CIRHR seminar for their helpful comments on an earlier draft.

\footnotetext{
Abstract:

The effects of different forms of collective representation (unions and special plans with and without binding arbitration) on faculty salaries are estimated for Ontario universities, 19702004. Compared to status-less faculty associations, unions had virtually no effect while special plans without binding arbitration led to lower salaries. Special plans with binding arbitration yielded higher salaries. The data also show severe compression and inversion in the age-salary profiles in the 2000s and large decreases in the salary differentials between full and associate professors. Average salaries were lower the higher the proportions of women faculty in the 1970s, but the effect dissipated and even reversed itself by the end of the sample. Finally, faculty salaries responded to the cost of living in the university's city and faculty salaries were higher, on average, in universities with higher average research productivity.
} 


\section{Faculty Salaries and Alternative Forms of Representation}

\section{Introduction}

As unionism declines there is increasing concern about a representation gap (Kaufman and Gottlieb Taras 2000,3) where employees want representation in the workplace but do not want, or are denied access to, traditional unionism. A commonly suggested solution is to implement some forms of nonunion employee representation. The Kaufman and Gottlieb Taras (2000) volume, Hirsch and Hirsch (2006), and the references cited therein consider various aspects of nonunion representation.

Faculty at Ontario universities provide an interesting experiment in adopting different amounts and types of employee representation. By the early 1970s the faculty at each university had formed associations that attempted to represent them collectively; but with no formal status, authority, or power. Over the next 30 years, this type of representation was rejected by faculty at all Ontario universities. Faculty at some universities chose union representation while others chose to negotiate special plans that provided levels of collective representation between unionism and the status-less faculty associations. At some universities faculty changed their form of representation two or three times over the years considered here.

This paper uses data on faculty salaries and the variation in representation over time and across universities to estimate the effects of the different types of representation on faculty salaries. Four types of representation are considered: no formal representation under the statusless faculty associations, unionism that included the right to strike, special plans where faculty did not have the right to strike and the university's governing board could reject settlements, and special plans with third party binding arbitration of any disputes. Several estimates are reported 
to allow for university specific effects, changes in the effects over time, and differences by faculty rank and age group.

To obtain credible estimates of the effects of employee representation one must control for the effects of rank and age or experience on faculty salaries. The salary differences across ranks and age or experience are important in their own right to both faculty and university administrations. They affect faculty incentives, job satisfaction, recruitment, and total salary costs as faculty age. There is a large literature on salary compression and occasional inversion across ranks and age groups for US faculty, including Hamermesh (1998), Scott and Bereman (1992) and Jennings and McLaughlin (1997). Barzebat (2004) makes a further contribution and provides a survey showing overall mixed results for US faculty. This paper provides what is to my knowledge the first evidence on compression and inversion for Canadian faculty by estimating salary differentials across ranks and age groups over the 1970 to 2004 period. The estimates show large changes in the average differentials between ranks (controlling for age) which implies large changes in the incentives faced by faculty over their careers. Controlling for rank, the age-salary profiles also changed dramatically over the period, largely driven by demographic changes.

Unfortunately, the aggregate data used in this study allow only a rough analysis of the relative salaries of men and women faculty. This is done by estimating the relationship between the percentage of women faculty and average salaries. The results show that the relationship changed substantially over the period, as one would expect given the big changes in women's position in academe over the period studied. Lastly, estimates of the effects of faculty research productivity and the relative cost of living in each university's city are reported. 


\section{Data}

The data cover full time, teaching and research faculty at fifteen Ontario universities, $1970 / 71$ to $2004 / 05$. To simplify the exposition, the first year is used to refer to the fiscal years so, for example, 2004 refers to the 2004/05 academic year. Only faculty holding the ranks of full, associate, or assistant professor are included and medical and dental faculty are excluded. All fifteen universities operated over the whole sample period so the data are not affected by the creation or conversion of new universities in Ontario. The fifteen universities made up virtually all of the Ontario university system in 1970 and roughly $95 \%$ of it in 2004

All of the universities are public, four year institutions that provide some graduate education. Five can be classified as research or doctoral. Another five are usually classified as comprehensive but they all offered Ph.D. programs in some disciplines over the period. The remaining five are classified as primarily undergraduate, but again, they all offered graduate programs in a few disciplines. Each university had at least 100 faculty in every year and the total number of faculty covered ranged from 7,047 in 1970 to 10,308 in 2004.

Since all of the universities are public, they all fell under the Ontario provincial jurisdiction and were subject to the same government policies and funding in each year. This makes it much more likely that the year dummy variables included in the estimation successfully control for the year specific effects of government funding and other policy changes.

Controlling for these year specific effects, in turn, makes the data more comparable across time.

The unit of observation is the average salary in a particular age group, rank, university and year. There are eight age classes (under 30, 30-34, 35-39, 40-44, 45-49, 50-54, 55-59, 60 and over) and three ranks (Assistant, Associate, and Full). Some age/rank categories are empty since, for example, no school ever has full professors under thirty. The average salary is also set 
to missing if there were too few faculty in the age/rank category to maintain confidentiality. The data were collected by Statistics Canada and distributed by the Canadian Association of University Teachers (CAUT). The all items Consumer Price Index, 1992=100, was used to generate real values.

The age categories are used as measures of experience. This is reasonable since all of the universities are four year schools and so most faculty at the assistant or higher rank have a Ph.D. as their highest degree. Further, another data set covering the same universities and years (but not including salaries) shows that age and 'years since highest degree' are very highly correlated.

Average real rental rates for two bedroom apartments in each university's city were collected for each year from the Canada Mortgage and Housing Corporation, the Ontario Ministry of Housing and Statistics Canada sources. While it is a very narrow measure of relative prices, it provides a measure of the cost of living that faculty face in each city and year. It has the advantage of being available for all cities and years, unlike more comprehensive measures of cities' relative costs.

The total number of publications of all document types (as counted by the Institute for Scientific Information (ISI)) is divided by the number of faculty to provide a measure of average faculty research productivity in each university and year. The percentage of women faculty in each university and year was purchased from Statistics Canada.

Table 1 reports the means and standard deviations of the variables in the data set with each observation weighted for the number of faculty in that age/rank category. An appendix with more details on the data and their sources is available upon request. 


\section{Baseline analysis}

Before estimating the effects of different forms of representation, some characteristics and determinants of salaries are reported. Salaries are specified to be a function of: rank, age group (as a proxy for experience), proportion of women faculty, apartment rents (as a proxy for the city's cost of living), publications per faculty member (a measure of faculty's average research productivity), fixed university effects, and fixed year effects. The effects of rank, age, and proportion of women faculty are allowed to vary over the sample period. To simplify the presentation, the regression equation is explicated in words rather than in the usual mathematical notation (which is quite intricate given the multiple indicator variables and interaction terms described below). But the full regression equation is available upon request.

The 'basic regression equation' specifies that the log of the average real annual salary in each age/rank category, university, and year is a linear function of:

1) Dummy variables for the associate and full professor ranks that capture the average salary difference between that rank and the next lower rank. ${ }^{1}$ The rank dummy variables are interacted with trend, trend squared, and trend cubed terms so that the estimated difference is allowed to vary over the years in the sample according to a third order polynomial.

2) Dummy variables for the seven elder age categories (under 30 is the base) to estimate the average salary difference between that age group and the under 30 base age group. Interactions with trend and trend squared terms allow the estimated impact of each age category to vary over the sample period according to a second order polynomial.

\footnotetext{
1 The associate professor rank dummy variable included in the regression equation and used to generate the estimation results below is slightly different from the one shown in Table 1. To capture the salary difference from the next lower rank, the associate dummy variable included in the regression equals one for observations on either the full or associate professor rank. The full professor dummy variable equals one for observations on full professors.
} 
3) Percentage of women faculty at that university in that year. Interactions with trend terms allow the estimated impact to vary over the sample period according to a third order polynomial.

4) Average number of publications per faculty member at that university in that year.

5) Real apartment rents in the city containing the university in each year.

6) Dummy variables for each year to capture fixed, year specific effects that impact salaries at all universities. 1970 is omitted so that the regression can keep its constant term.

7) Dummy variables for each university to capture fixed, university specific effects that impact salaries. ${ }^{2}$ The dummy variable for Brock University is omitted so that the regression can keep its constant term.

8) Independently and identically normally distributed disturbance term for each age/rank category, university, and year.

The basic regression equation is estimated according to OLS with each observation weighted for the number faculty in that age/rank/university/year category (i.e. weighted by the number of faculty covered by that average salary). Weighting by the number of faculty covered by the observation ensures that the estimates reflect the composition of the individual faculty members in the fifteen universities. The estimated coefficients and t-statistics are difficult to interpret by themselves so they are reported in the appendix, in column 1 of Table A1. Instead, Figures 1, 2, and 3 show the estimated effects of rank, age and percentage of women faculty over

2 Other studies of faculty salaries typically include dummy variables for each category of university, which are doctoral/research, comprehensive, and primarily undergraduate in this study. Including dummy variables for every university (as is done here) provides controls for the different types of universities, but without forcing schools in the same category to have the same fixed effect. Thus they provide more adjustment or controls for the effects of university type than dummy variables for the university categories. Further, if a dummy variable for the comprehensive university category, for example, was included; one of the university specific dummy variables in the comprehensive category would have to be dropped for the estimation. Thus there would be no increase in the controls or adjustment for university type. The same holds for the other categories. 
the period along with $95 \%$ confidence intervals.

Before discussing the estimation results it is helpful to set out the timing of a typical faculty member's career in Ontario (and most other Canadian) universities. Faculty are usually considered for tenure after four to six years in a full time academic position. They usually hold the rank of assistant professor over these years, but may spend some of this time as lecturers. Promotion from assistant to associate usually occurs in the same year as the granting of tenure, but it is not uncommon for the promotion to occur in subsequent years. Stronger candidates can obtain tenure and promotion more quickly while weaker candidates may 'stop the [tenure] clock' by taking leaves of absence at other schools or restart the tenure clock by getting a new job at another school. Some assistant professors in the data set are not in tenure stream positions and are never promoted to associate professor but they make up only a small proportion of the faculty covered by the data set. Given the above, it is clear that promotion to associate professor and age do not move in lock step. While they are clearly related, there exists independent variation between rank and age and so their separate effects can be estimated.

After receiving tenure and promotion to associate professor, faculty are promoted to full professor or remain associates until their retirement. Promotion to full professor usually occurs after ten to fifteen years at the associate rank and often much later. Among the Ontario schools considered here, the percentage of associate professors who were 50 or older rose from around $25 \%$ in the early 1970 s to around $35 \%$ by 1990 and remained stable at that level for the rest of the period. The percentage of associates aged 60 or above rose from around $20 \%$ at the start of the sample period to over $30 \%$ by the end. So a significant and increasing proportion of tenured associate professors remain at that rank for their entire careers so, again, there is independent variation between the age and rank of faculty. 
Since many faculty do not progress to full professor, the rank differences shown in Figure 1 include a substantial sample selection component and are not good predictors of the increases that an individual faculty member (chosen at random) would receive from his/her promotion. However, since selection is involved at both promotions and the estimates control for age, the increments do provide a measure of the average return paid for the higher quality (or other characteristics) and performance required for promotion, compared to the characteristics and performance that keep faculty at a lower rank.

Figure 1 shows that the percentage difference in average salary between associate and full professors, controlling for age and the other right hand side variables, fell dramatically from over $35 \%$ at the start of the sample to $17 \%$ by the mid 1990 s and it remained around that level for the rest of the sample. ${ }^{3}$ The difference from assistant to associate was much more stable over the period, starting at $20 \%$, falling to a low of around $18.5 \%$ in the late $1970 \mathrm{~s}$, rising to $21.4 \%$ in 1997 and then ending back at $20 \%$ in 2004 . In dollar terms, the differences between full and associates are always larger than the differences between associates and assistants since the percentage differences in Figure 1 refer to different bases. For example, if the analysis is redone in terms of dollar amounts, in 2004 associates are estimated to receive $\$ 12,000$ more than assistants (in 1992 dollars) while fulls receive $\$ 13,500$ more than associates.

The large decrease in the increment for full professors (controlling for age) contrasts with the stable salary ratios by rank, 1971-2001, reported in Hamermesh (2002 and 1998) for US faculty. This difference is not due to the controls for age or the other variables because rank

3 For factors measured with dummy variables (e.g. rank, age group, form of representation) the percentage difference in average salaries reported in the Figures or Table 2 equals $100\left(\mathrm{e}^{\mathrm{x}}-1\right)$ where $\mathrm{x}$ is the effect measured by the regression equation. This transformation is used since the dependant variable is in $\log$ form. For factors measured with continuous variables (e.g. proportion of women faculty, publications per faculty, rents) the regression coefficient is multiplied by 100 to obtain the percentage change in average salaries from a one unit change in the variable. 
ratios, like those reported in Hamermesh, also show Ontario full professor salaries falling relative to assistants and associates over the period. (These are not shown to save space). Other US studies of salary compression show mixed results with changes in rank ratios moving in either direction according to different data sets and breakdowns of the data. See Barbezat (2004) for a survey.

Controlling for rank, the effects of age are best seen by showing (as in Figure 2) the estimated age-salary profiles for selected years, relative to the under 30 salary in that year. The profiles summarize the effects of age on salaries over the period but the estimated effects of each age category for all years are available upon request. Note that the profiles for the omitted years move smoothly between those shown in Figure 2 since the estimated impact of each age category is a quadratic function of the year. If the age profiles are estimated in terms of dollar amounts rather than percentage changes, they have the same shapes and the same results obtain.

Figure 2 shows that the 1973 salary-age profile is like those shown in textbooks. It is concave, with salaries rising most quickly for youngest faculty and then rising more and more slowly over the older age groups. The 1983 salary-age profile rises slightly more quickly for the younger age groups, but rather than becoming flatter with age, it becomes steeper over the middle portion which covers faculty 40 to 49 . The 1993 profile rises much more slowly than both 1983 and 1973 initially and it is also not concave. Its steepest sections occur even later, with the largest age related salary increases accruing to faculty aged 45 to 54 .

The changing demographics of faculty provide an explanation for why the steepest portions of the salary profiles moved to older ages over time. Universities in Ontario, like those in the rest of Canada and the United States, expanded rapidly and hired large numbers of faculty from the middle 1960 s to the early 1970 s at relatively high starting salaries. This flattened the 
salary-age profile in the early 1970 s by increasing young faculty's salaries. Then, as this dominant cohort aged, (in their 40s in the 1980s, in their 50s in the 1990s, in their 60's and retiring in the 2000's), their relatively high salaries (after controlling for other factors) raised that section of the profile.

The 2003 profile shows severe and statistically significant salary inversion with the age 30-34 average salary seven percent below the under 30 average. There is also salary compression with no age related increases in salaries, controlling for rank, from the 30-34 to the 40-44 age groups. ${ }^{4}$ The inversion and compression are due to the very large numbers of younger faculty who have been hired since 1998 at relatively high salaries. The hiring boom occurred because of the rapid expansion of all Ontario universities in response to large increases in government funding since 1998 (Martinello 2006) and to replace the large retiring cohort mentioned above.

The basic regression equation was re-estimated with fourth order polynomials for the effects of rank and third order polynomials for the effects of the age groups but the results were very similar to those presented above.

Figure 3 provides some rough evidence on differences between men and women's salaries over the sample period, controlling for age and rank. In the early 1970s, average salaries were at least $0.75 \%$ lower if the percentage of women faculty was one point higher. But the impact of the gender mix declined rapidly over the 1970s and early 1980s. By 1985 the estimate had risen to $-0.1 \%$, but it was still different from zero at the $95 \%$ confidence level. The point estimate remained around $-0.1 \%$ and statistically significant until 1997 , after which it increased to zero and became positive. In 2004 average salaries were estimated to be $0.1 \%$ higher if the

4 If a third order polynomial for the impact of each age group is specified then the 30-34 average salary still falls by $7 \%$ in the 2003 profile, but the average salaries over the 35-39 and 40-44 age groups rise very gently with age. However the differences in the point estimates are not statistically significant. 
percentage of women faculty was one point higher and the estimate is statistically significant. This result, however, does not necessarily imply that women's salaries are higher than men's in 2004. A positive effect also obtains if universities with higher proportions of women faculty pay higher salaries to all faculty (controlling for the other right hand side variables) while keeping women's salaries below men's. Other evidence on the effects of gender on Canadian faculty salaries is scarce. Warman, Woolley and Worswick (2006) show that women's salaries increased relative to men's in Canadian universities over the 1970-2001 period, but remained below men's in 2001.

Finally, Table 2 reports the estimated effects of rental rates and average publications per faculty. Column A shows that one more publication per faculty member per year, averaged over all faculty, is associated with a $2.5 \%$ increase in average salaries and the estimate is statistically significant. Column A also shows that average salaries responded positively and significantly to higher costs of living in the university's city as measured by real apartment rental rates.

\section{Faculty representation in Ontario universities}

Figure 4 shows the percentage of faculty in each form of representation over the sample period. By the early 1970s all faculty had formed associations that represented them collectively at each university, but the associations had no authority or power to negotiate any terms or conditions of employment with university administrations. The situation was often described as 'collective begging' (Thompson 1975, 258) and it is classified as no formal representation here.

Ontario labour relations legislation made unionization fairly easy for faculty who wanted

it. Faculty were covered by the private sector legislation and Labour Relations Board so they received all of the rights and protections of private sector workers. These included the right to 
strike in support of contract negotiations, freeze provisions during organizing, no mandatory representation vote in the years before 1996, mandatory grievance procedures in the collective agreement, duty of fair representation, and first contract arbitration after 1986. The Labour Board also set bargaining units that were most favourable to faculty unions, by including all faculty in the university (up to and including coordinators, chairs and directors) and sometimes professional librarians in a single unit. Further, Cameron $(1991,365)$ reports that many university administrators were ambivalent to faculty unionization. While they considered it distasteful and inappropriate, they sympathized with the unions goals of participatory management and did not mount strong opposition to the unions.

In the mid 1970s, faculty at four universities unionized. Thompson $(1975,260)$ and Penner $(1978,73)$ report that the most important reason for unionizing was job insecurity caused by the contraction of Ontario universities after their rapid expansion from the mid 1960s to the early 1970s. Other reasons consisted essentially of a desire for representation in the workplace and this desire for voice also motivated the organizing that occurred later. Universities had grow very rapidly since the mid 1960s and they continued to grow over the sample period but with significant starts, stops, and contractions. Faculty found themselves working in institutions that were more like public corporations or public utilities than collegial communities of scholars (Cameron 1991, 343) and they were subject to often changing policy regimes. In response faculty turned to union representation for protection from arbitrary treatment (Thompson 1975, 260); clear and consistent procedures for appointments, promotions and tenure (Cameron 1991, 365); and grievance procedures with binding third party arbitration (Cameron 1991, 365). Higher salaries were never given as a primary motivation for unionization in the discussions of faculty unionism cited above. Figure 4 shows that there were two periods of rapid union growth, 
1975 to 1980 and 1996 to 1998 . It is notable that the second burst of unionization followed a severe contraction in the Ontario university system, (see Martinello 2006 for details) which adds more weight to the job insecurity motivation for unionizing. After 1998 union representation covered over $60 \%$ of faculty.

Despite the growth of faculty unionism, few academics embraced unionism eagerly (Thompson 1975 261). For example, all of the faculty unions remained independent and did not affiliate with other teacher, professional or public sector unions, nor with any of the labour federations. ${ }^{5}$ Further, faculty at some universities rejected union representation. They felt that unions imposed an adversarial 'industrial model' that brought creeping legalism and the decline of merit, and that it was inconsistent with collegiality and professionalism; especially when they considered the prospect of a strike (Penner 1978, 73). These universities developed special plans as alternatives to union representation.

Special plans are contracts signed by the administration and faculty association that give the association the right to negotiate some terms of employment with the administration as well as some recourse to dispute resolution procedures such as mediation, fact finding, and third party arbitration. ${ }^{6}$ In contrast to the practice in other provinces, some of the special plans allowed the university's governing board to reject a negotiated or arbitrated settlement at the very end of the process. Opponents of this type of representation argued that negotiated settlements or arbitration awards would be reduced so that they would not be rejected, even if the boards never actually rejected a settlement or award (CAUT 1982, 8). In response, other universities and

5 This applies to Ontario. Some faculty unions in other provinces did affiliate with their provincial labour federations.

6 At some universities the special plan contract was simply called the 'memorandum of agreement' or just the 'agreement'. 
faculty associations negotiated special plans with third party binding arbitration as the final dispute resolution procedure (SPBA). ${ }^{7}$ One drawback of all the special plans is that they only covered salaries and whatever other issues the administration agreed to include. In practice, they did not cover the broad range issues found in union negotiated collective agreements.

Figure 4 shows that special plans requiring governors' approval (SPRGA) first appeared in 1977 and covered around $20 \%$ of faculty over the middle part of the sample. But there was considerable turnover within this form of representation as faculties tried and then abandoned it in favour of unionization or a special plan with binding arbitration. By 1998 only one university retained SPRGA and, not surprisingly, they had the most stringent requirements for rejection by the governing board. But even they have now abandoned it. Their faculty unionized in 2006. Special plans with binding arbitration (SPBA) were first introduced in the mid 1980s and they covered roughly one third of faculty over the rest of the sample.

Over the period of the sample, faculty at every university had at least two types of representation (where no formal representation is counted as a type). Faculty at two universities tried three types of representation and at one university faculty tried all four types of representation over different years in the sample. Finally, note that Ontario faculty went from no formal collective bargaining in the early 1970 s to $100 \%$ of faculty represented unions, SPBA or SPRGA by 1998 and thereafter.

\footnotetext{
7 The University of Toronto, 1985 and after, is included in this group even though their special plan
} calls for binding third party arbitration, with no governing council approval, at most every second year. 


\section{Faculty salaries by type of representation}

\section{a) Overall average effects}

To start the analysis, dummy variables for each type of representation are included in the basic regression equation. The union dummy variable captures the overall effect of union representation (as a percentage of average salary); averaged over all years, schools, ranks and age groups; compared to the alternative of no formal representation; where single dummy variables are also used to control for the effects of SPNA and SPBA. The SPRGA and SPBA dummy variables give analogous estimates of their average effects. Recall that the basic regression equation also controls for university specific effects with separate dummy variables for each school and year specific effects with dummy variables for each year in addition to the variables discussed in the baseline analysis.

Column B of Table 2 shows that the estimated overall effect of union collective bargaining is small. Unionization is estimated to lower average salaries by $0.3 \%$ and the estimate is not significantly different from zero. Special plans that require governors' approval are estimated to lower average salaries by $1.68 \%$ while special plans with binding arbitration are associated with $1.26 \%$ higher average salaries. Both of the special plan effects are statistically significant.

Adding the representation variables does not change the estimated salary effects of rank, age, or the percentage of women faculty significantly. This is also true for the estimates allowing university specific and time varying effects that follow. They are all very similar to the results shown in Figures 1, 2, and 3 and so they are not reported. However, the regression coefficients for ranks, age, and percentage of women are reported in Table A1 for every case, and graphs of their estimated effects are available from the author. 


\section{b) Allowing university specific effects}

One concern with the estimates above is that there may be university specific characteristics that are correlated with the type of representation chosen and with salaries, but whose effects are not fully captured by the university specific dummy variables. Possible characteristics include the mix of disciplines and professional schools, the management style of the administrations, the earlier history of the school (e.g. old religious affiliations) or other characteristics that are not directly observable. These would bias the estimated effects of faculty representation. To eliminate the possible biases, separate dummy variables for the different types of representation at each university are included in the basic regression equation. These produce university specific estimates of the effects of the various types of representation. The university specific estimates are then averaged and reported in column $\mathrm{C}$ of Table 2.

Allowing university specific effects reduces the size and precision of the estimated effects of unionization and special plans requiring approval, but the basic conclusions are unchanged. Unionization has essentially no impact on average salaries while SPRGA has a small negative impact. The estimated effects of special plans with binding arbitration are virtually unchanged (positive and significant) when university specific effects are allowed. The effects of rank, age, gender proportion and rental rates are similar to the earlier estimates but the estimated effects of publications per faculty member becomes very small and statistically insignificant.

\section{c) Allowing time varying effects}

Another consideration is whether the effects of faculty representation varied over the long 
time span of the sample. Unfortunately one cannot estimate time varying effects of unions, SPRGA, and SPBA simultaneously and adjust for year specific effects after 1995 because $100 \%$ of faculty are covered by unions, SPRGA or SPBA after that year. (See Figure 4.) Further, while estimation is numerically possible over the 1985 to 1995 period, it is not recommended because more than $90 \%$ of faculty are covered by the representation variables over this period. Thus the base or control group would be quite small and the estimates open to serious question. One solution is to estimate the basic regression equation with time varying effects for only unionization and SPRGA included, and note that the comparison group for the estimates changes in 1985 . Before 1985 there are no special plans with binding arbitration, so the estimates give the impacts of unions and SPRGA compared to the alternative of no formal representation. From 1985 to 1995 , the comparison group is the roughly one third of faculty covered by SPBA and the few faculty (less than 8\%) with no formal representation. After 1995 the estimates show the effect relative to the effects of SPBA only. To sharpen the estimates, observations on faculty with no formal representation, 1985 to 1995 are removed from the sample. Thus, after 1985, the estimates show the impacts of unions and SPRGA compared to the alternative of a special plan with binding arbitration. If the observations on faculty with no formal representation (1985-95) are not removed, the same basic conclusions follow but, not surprisingly, more of the estimates are statistically insignificant.

The basic regression equation was re-estimated with dummy variables for union and SPRGA representation for four or five year time periods. The results are shown in Figure 5 and the regression coefficients are reported in Table A1. The estimated effects of union and SPRGA representation do vary significantly over the sample period but the overall results are not very different from the earlier estimates. Figure 5 shows that, compared to no formal collective 
representation, unionization has a small (less than $1 \%$ ) negative but statistically insignificant impact on salaries over the 1975 to 1984 period. Special plans requiring approval have statistically significant negative effects ranging from $-5.8 \%$ to $-1.9 \%$ over the 1977 to 1984 period when compared to salaries under no formal representation.

Figure 5 also shows that, compared to SPBA, unionization generally continues to have small and insignificant negative effects from 1985 to 1996 . In the 1985 to 1988 time period the point estimate effect is larger (-1.35\%) and significant, but it is around $-0.5 \%$ and insignificant from 1989 to 1996. After 1996, salaries under union representation fall sharply relative to those in schools with SPBA with differences reaching $-4.5 \%$ in the 2001-04 time period. Salaries under SPRGA were significantly below those awarded under SPBA after 1985 although the 1989-92 estimate is not statistically significant. The negative impact increased sharply to - $4.9 \%$ by the end of the sample period. Note that salaries at all Ontario universities rose sharply after 1997. Figure 5 shows that they increased much more, on average, at universities with SPBA than at the universities with unions or SPRGA.

\section{d) Effects by rank and age}

Given the big changes in salary differentials across ranks and ages shown above, it is interesting to consider whether the changes occurred under all three forms of representation. Unfortunately, similar to the problem discussed in part c, one cannot estimate time varying age or rank effects for all three types of representation simultaneously and still maintain controls for year and university specific effects. A partial solution is to estimate union and nonunion effects of ages and ranks over the sample, keeping in mind that the nonunion comparison group changes from no formal representation, to a mix of special plans, to almost all SPBA as described above. 
The basic regression equation is re-estimated with separate polynomials for union and nonunion rank and age group effects. Again, third order polynomials are specified for ranks and second order polynomials for each age group. Single dummy variables for union, SPRGA, and SPBA representation are also included and their estimated coefficients turn out to be very similar to the overall average single dummy variable effects reported in Column B of Table 2 (see Table A1). The estimated differences between the union and nonunion age and rank effects do not change substantially if the single dummy variables for representation are excluded.

Union and nonunion rank differentials are shown in Figure 6. Both union and nonunion faculty experienced the same dramatic decrease in the salary differential between full and associate professors. This is expected for union faculty because it is well known that union collective representation and bargaining tend to reduce salary differentials in the workplace. But it is not surprising that nonunion faculty had the same decrease. As shown above, all nonunion faculty moved to more collective representation over the sample period so they would experience many of the same pressures for decreasing salary differentials that occur under unions. After 1997, however, the union and nonunion differentials diverged sharply. Most of the nonunion universities were covered under SPBA after 1997 and Figure 6 shows that they gave relatively more of their more rapidly rising salaries to full professors. The difference between full and associate nonunion professors increased from $17.4 \%$ in 1997 to $20.9 \%$ in 2004 . Unionized faculty did the opposite and the difference between their associates and fulls declined further to $14 \%$ after a roughly ten year plateau at around $17.3 \%$. By 2004 the associate/full difference is estimated to be well below the difference between assistants and associates.

At nonunion universities the percentage difference between associate and assistant professors behaved like the overall differential shown in Figure 1. It varied a few points over the 
sample period, but ended back where it started at around $20 \%$. The percentage difference between associates and assistants was lower under unionism early in the sample (at around 14\%), but it trended upwards and was almost equal to the nonunion difference by 2004 .

Figure 7 shows that union and nonunion age-salary profiles are similar and show the same basic changes. ${ }^{8}$ There are, however, two notable differences. First, the salary inversion in the 2003 profile is larger in union schools and second, controlling for rank, older faculty earn more in union schools over the whole sample period. The similarity of the profiles is not too surprising because union and nonunion universities experienced similar changes in the age distributions of their faculty, due to the same growth and contractions periods.

\section{Comparisons with the literature}

The union and special plan estimates presented above differ from those reported in other studies of Canadian faculty salaries. Rees, Kumar and Fisher (1995) and Hosios and Siow (2004) both report small positive and statistically significant effects of unionization using essentially the same data on Canadian university faculty salaries 1972 to $1991 .{ }^{9}$ They also report positive effects for special plans but the estimates are often not significantly different from zero. Their methods differ from the above in that they do not adjust for faculty ages, research productivity or cost of living in the university's city. More importantly they do not distinguish between special plans requiring Board of Governors' approval (SPRGA) and special plans with binding arbitration (SPBA). They use data from all Canadian provinces, but that does not

\footnotetext{
8 There is no 1973 union age-salary profile because no universities were unionized until 1975. The 1973 nonunion age-salary profile is just like the one shown in Figure 2.

9 Hosios and Siow (2004) also develop a theoretical model of the effects of union representation and report estimates of the effects of unionization and special plans on total university revenues, salary inequality and faculty research productivity.
} 
account for the differences in the results. If the sample of Ontario universities used here is restricted to the 1972 to 1991 period, and their regression specification and coding of representation forms is applied, then results similar to Rees et al. (1995) and Hosios and Siow (2004) obtain.

As for comparisons with the US literature, there is little consensus on the impact of unionization on faculty salaries in the US. For example, Ashraf (1997), Rees (1992) and Barbezat (1989) all provide surveys of the US literature showing mixtures of negative, positive and zero impacts of union representation. Rees (1992) and Ashraf (1997) comment that the estimates are not robust to the research design or database. One firm conclusion from the literature is that the effect of union representation on faculty salaries is less than the conventional 10 to $15 \%$ union impact cited in textbooks. It is clear that the estimates for Ontario faculty cited above are consistent with that result.

\section{Conclusions}

From 1970 to 2004 faculty at Ontario universities experimented with different forms of collective representation and the estimates above show that their salaries varied with the type of representation. Averaged over the whole sample, unionism had essentially no effect when compared to salaries under status-less faculty associations (i.e. compared to no formal representation). Achieving higher salaries was never cited as one of the major motivations for faculty unionization and the results are consistent with that.

Faculty who negotiated special plan collective contracts requiring the university's governing board's final approval generally had lower salaries than those under unionism, no formal representation, or other special plans. Evidently the formal bargaining arrangements and 
dispute resolution mechanisms under this type of plan provided effective tools for keeping salaries below those negotiated or awarded at other universities. The expressed concern that negotiated or arbitrated settlements would be made more modest so as to be approved by the governing board appear to have been well founded. The results also help explain why all faculty who adopted this type of special plan ultimately rejected it for one of the other forms of representation.

Special plans with third party binding arbitration as the final dispute resolution mechanism were successful in raising faculty salaries compared to those under unions, special plans requiring approval, and no formal representation. This was especially true after 1997 when the Ontario university system expanded rapidly and all faculty salaries were rising. Salaries under special plans with binding arbitration rose much more quickly than those under other types of representation (mainly union at that time) and they allocated relatively larger salary increases to full professors.

Controlling for age and the other right hand side variables, the salary differential between full and associate professors fell sharply, regardless of the type of representation, over the 1970 to 2004 period. While one can construct caveats about changing composition, selection, and standards within and between the full and associate professor ranks (none of which can be tested with the data used here), it seems clear that there was a decline in merit based salary differentials over the sample period. Specifically there was a decline in the return to the characteristics and performance that enable a promotion from associate to full professor. Given this decline in the return, it is not surprising that the proportion of older associates progressing to the rank of full professor decreased over the sample.

The overall decrease in the full/associate differential is consistent with the usual result 
that collective bargaining decreases merit and skill based differentials. Ontario university faculty went from zero unionism in the early 1970 s to over $60 \%$ of faculty covered by union collective bargaining after 1997 . Moreover, the remaining $40 \%$ of faculty covered by special plans were also doing collective bargaining (strictly speaking) and so the same forces that shape union agreements would also be present and lead to similar outcomes. That said, the nonunion (special plan) schools did reverse the decline in the full/associate differential at the end of the sample while it declined further under union collective bargaining.

Other findings show that, controlling for rank, there is serious inversion in the age-salary profile in the 2000s across all universities, although it is more severe among unionized faculty. Average salaries were lower in universities with higher proportions of women faculty in the 1970s, but the effect dissipated and even reversed itself by the end of the sample. Finally, faculty salaries increased with the cost of living in the university's city as measured by apartment rents and faculty salaries were higher, on average, in universities with higher average research productivity. 


\section{References}

Ashraf, Javed (1997) “The Effect of Unions on Professors' Salaries: The Evidence over Twenty Years" Journal of Labor Research Vol. 18 \#3. pp. 439-50.

Barbezat, Debra A. (1989) "The Effect of Collective Bargaining on Salaries in Higher Education” Industrial and Labor Relations Review Vol. 42 \#3 pp. 443-55.

Barbezat, Debra A. (2004) “A loyalty tax? National measures of academic salary compression”. Research in Higher Education Vol. 45 \#7 November 2004 pp. 761-76.

Cameron, David M. (1991) More than an Academic Question (Halifax: Institute for Research on Public Policy).

Canadian Association of University Teachers (CAUT) (1982) Bulletin (February 1982) p. 8.

Hamermesh, Daniel S. (2002) "Quite Good News - For Now." Academe Vol. 88 \#2 Mar/Apr 2002 pp. 20-42.

Hamermesh, Daniel S. (1998) "Salaries. Disciplinary Differences and Rank Injustices" Academe Vol. 84 \#3 May/June 1998 pp. 20-4.

Hirsch, Barry T. and Jeffrey M. Hirsch (2006) "The Rise and Fall of Private Sector Unionism: What Comes Next?" Proceedings of the Labor and Employment Relations Association. Vol. 58

Hosios, Arthur and Aloysius Siow (2004) "Unions without rents: the curious economics of faculty unions" Canadian Journal of Economics Vol. 37, \#1 pp. 28-52.

Jennings, Kenneth M. and Frank S. McLaughlin (1997) "Measuring and Correcting Inversion in Faculty Salaries at Public Universities" Public Personnel Management Vol. 26 \#3 pp.345-57.

Kaufman, Bruce E. and Daphne Gottlieb Taras (2000) Nonunion Employee Representation (M.E.Sharpe: New York).

Martinello, Felice (2006) "University Revenues and Faculty Salaries in Ontario: 1970/71 to 2003/04” Canadian Public Policy, Vol. 32, \# 4, pp. 349-372.

Penner, R. (1978-79) "Faculty Collective Bargaining in Canada: Background, Development and Impact" Interchange Vol. 9 No. 3 pp. 71-86

Rees, Daniel I. (1993) “The Effect of Unionization on Faculty Salaries and Compensation: Estimates from the 1980s" Journal of Labor Research Vol. 14 \# 4 pp. 399-422. 
Rees, Daniel, Pradeep Kumar, and Dorothy Fisher (1995) “The Salary Effect of Faculty Unionism in Canada" Industrial and Labor Relations Review, Vol. 48, \#3 pp. 441-51.

Scott, Joyce A. and Nancy A. Bereman (1992) "Competition versus Collegiality" Journal of Higher Education Vol. 63 \#6 pp.684-98.

Thompson, Mark (1975) "The development of Collective Bargaining in Canadian Universities" Proceedings of the annual winter meetings- Industrial Relations Research Association vol. 28 , pp. 257-65

Warman, Casey, Frances Woolley and Christopher Worswick (2006) "The Evolution of MaleFemale Wages Differentials in Canadian Universities: 1970-2001" Queen's Economics Department Working Paper No. 1099. Queen's University, Kingston, Ontario, Canada. 
Table 1.

Means and Standard Deviations, weighted by number of faculty in age/rank categories

\begin{tabular}{lrr}
\multicolumn{1}{c}{ Variable } & Mean & Std. Dev. \\
\hline Real average salary in 000's of 1992 dollars & 73.851 & 15.721 \\
Percentage of Women Faculty & 17.643 & 7.938 \\
Number of publications per faculty member & 1.348 & 0.937 \\
Real apartment rents in 00's of 1992 dollars & 6.576 & 0.971 \\
union dummy variable & 0.389 & 0.487 \\
SPRGA dummy variable & 0.125 & 0.330 \\
SPBA dummy variable & 0.190 & 0.392 \\
Full professor dummy variable & 0.373 & 0.484 \\
Associate professor dummy variable & 0.389 & 0.488 \\
Assistant professor dummy variable & 0.238 & 0.426 \\
age under 30 dummy variable & 0.018 & 0.133 \\
age 30 to 34 dummy variable & 0.098 & 0.298 \\
age 35 to 39 dummy variable & 0.155 & 0.362 \\
age 40 to 44 dummy variable & 0.174 & 0.379 \\
age 45 to 49 dummy variable & 0.173 & 0.378 \\
age 50 to 54 dummy variable & 0.158 & 0.365 \\
age 55 to 59 dummy variable & 0.131 & 0.337 \\
age 60 and over dummy variable & 0.092 & 0.289 \\
Number of faculty in age/rank categories & 33.001 & 30.875 \\
(unweighted) & &
\end{tabular}

Number of age/rank category observations $=9,171$ 
Table 2. Estimates of effects on average salary (expressed as percentages)

\begin{tabular}{cccc} 
Variable & Column A & $\begin{array}{c}\text { Column B } \\
\text { Using Single }\end{array}$ & $\begin{array}{c}\text { Column C } \\
\text { Allowing University } \\
\text { Specific Effects }\end{array}$ \\
\hline Real rental rates & 3.454 & 3.076 & 3.234 \\
& $(17.07)$ & $(14.39)$ & $(14.09)$ \\
Publications per & 2.473 & 1.882 & -0.087 \\
faculty member & $(15.64)$ & $(10.71)$ & $(-0.36)$ \\
union & & -0.273 & -0.043 \\
& & $(-1.12)$ & $(-0.16)$ \\
SPRGA & & -1.676 & -0.706 \\
& & $(-7.14)$ & $(-2.22)$ \\
SPBA & & 1.257 & 1.327 \\
& & $(3.96)$ & $(3.99)$ \\
R & & & 96.1 \\
N & & 95.9 & 9171
\end{tabular}

$\mathrm{t}$ statistics in parentheses 
Figure 1. Average salary difference compared to next lower rank

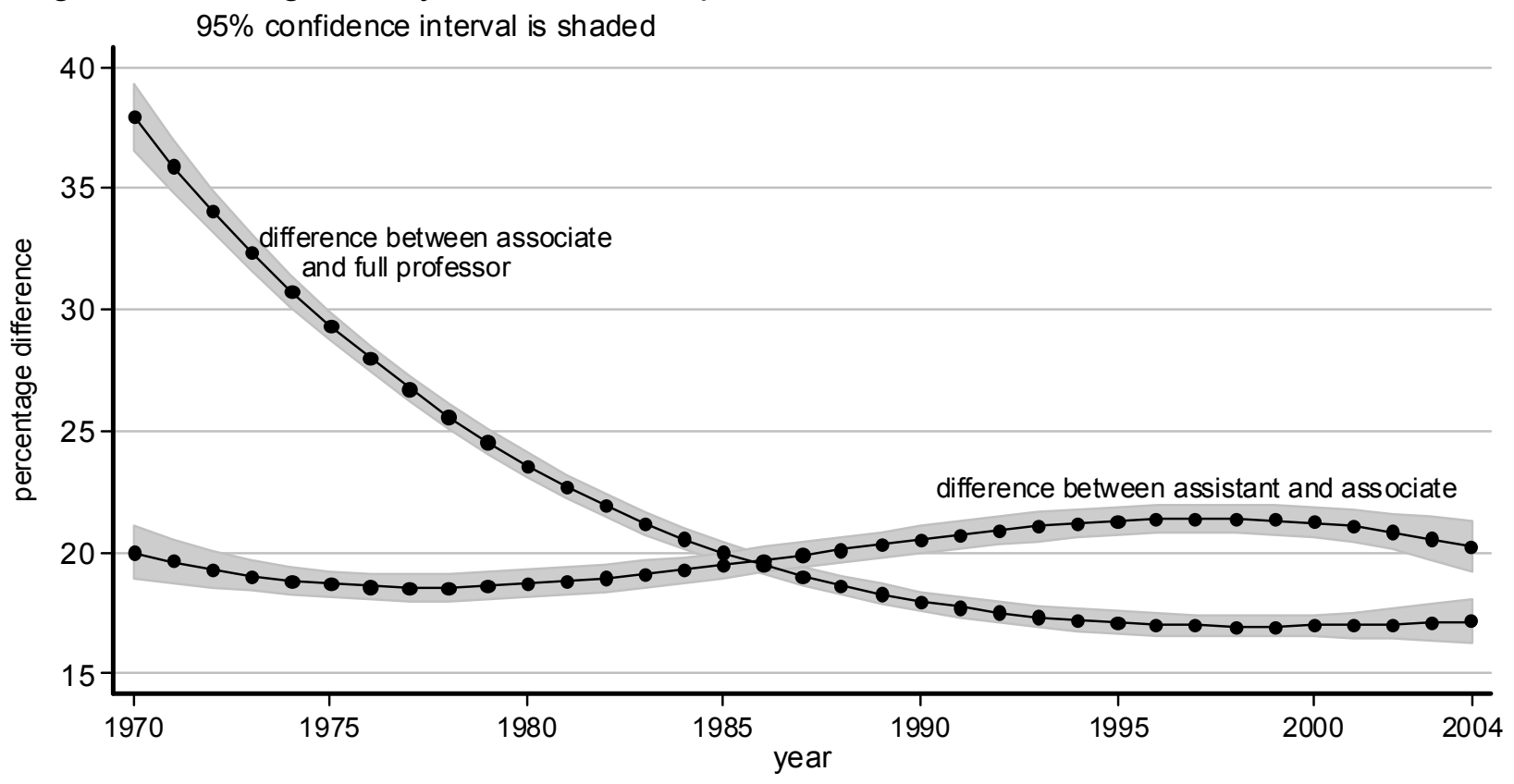

Figure 2. Salary-age profiles, relative to the under 30 age group, for selected years

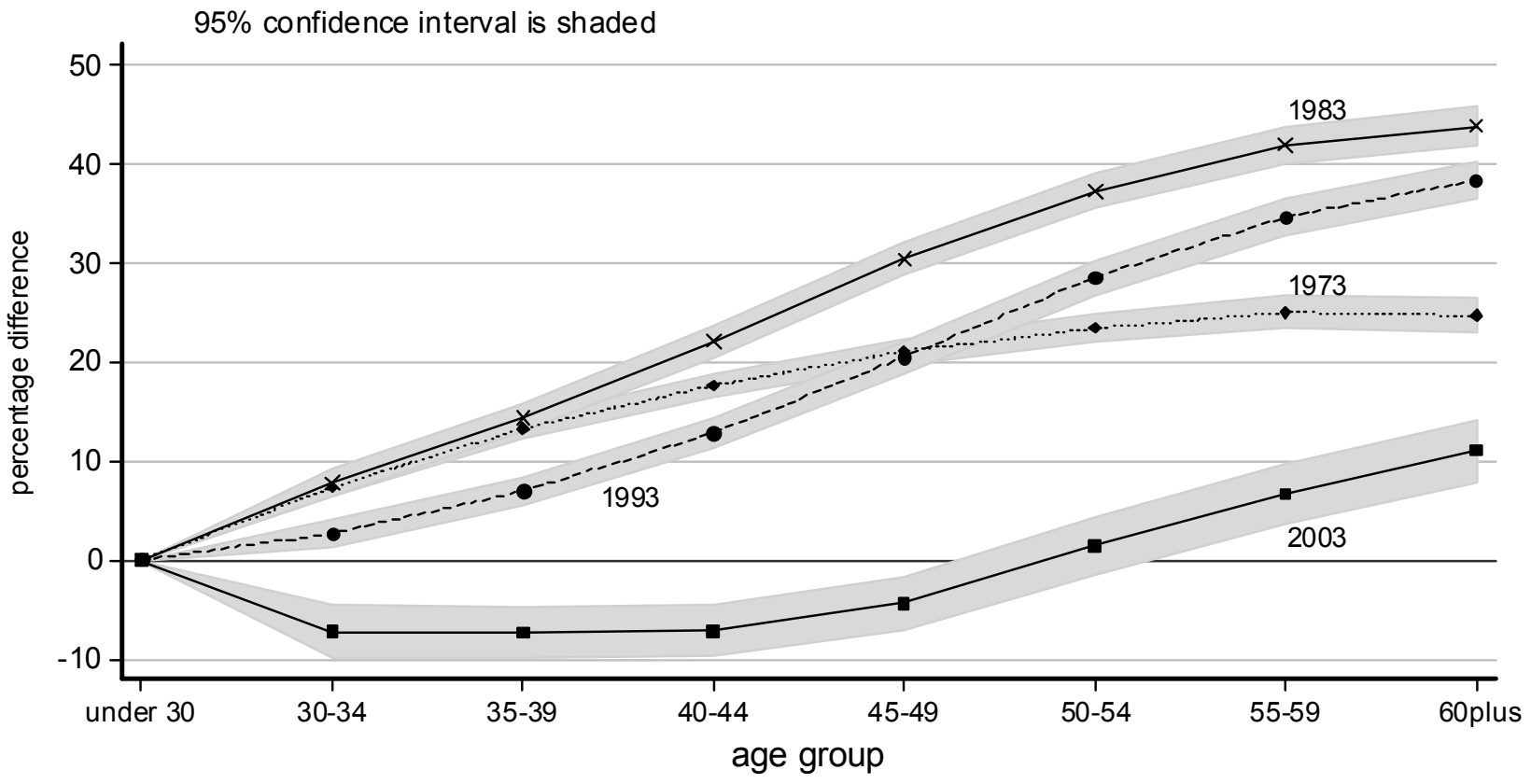


Figure 3. Average salary impact of one point higher percentage of women faculty

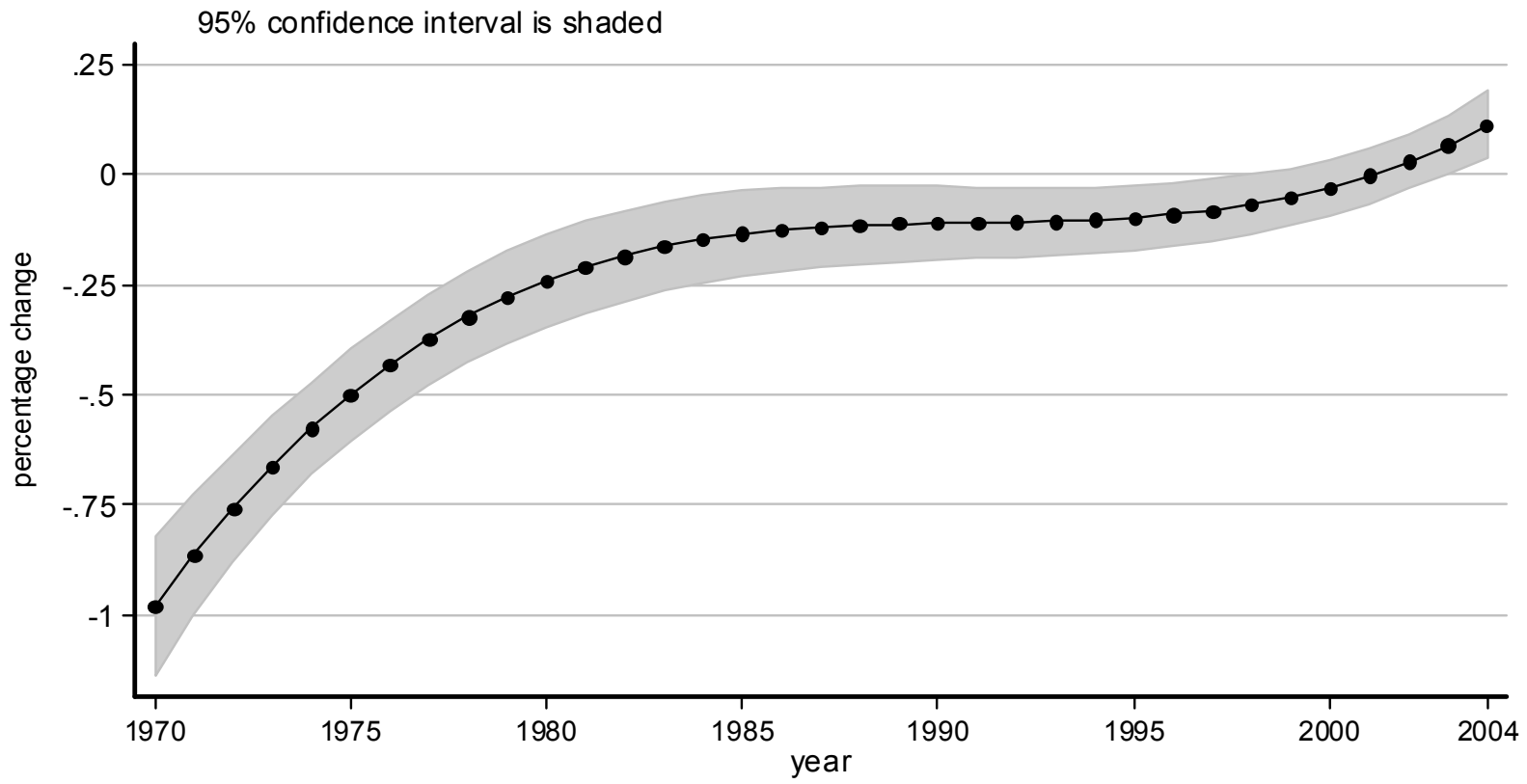

Figure 4. Percentage of faculty with formal collective representation

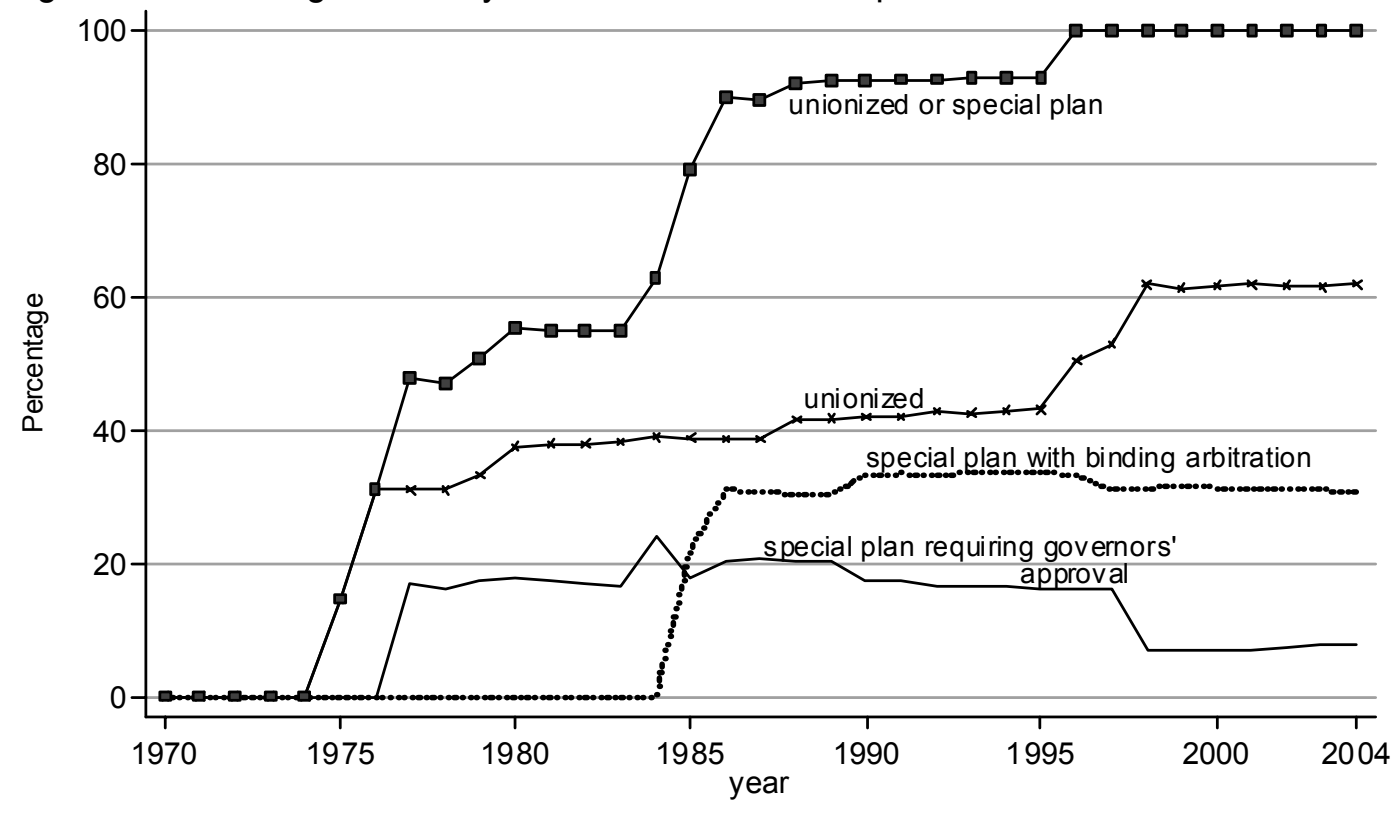


Figure 5. Average impact on salaries

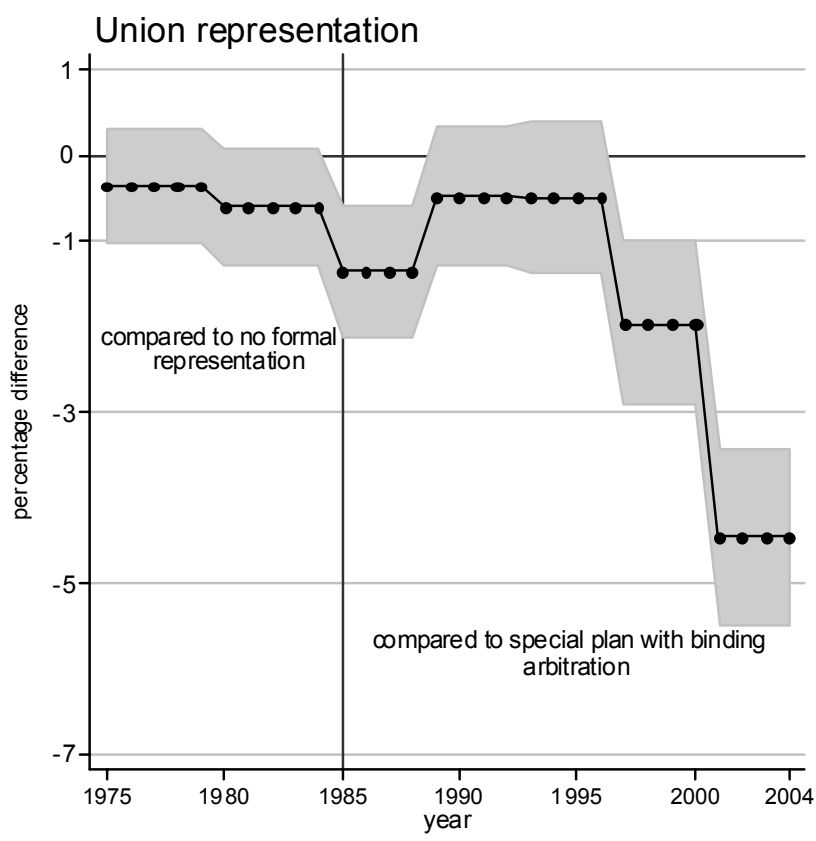

$95 \%$ confidence interval is shaded

Special plan requiring governors' approval

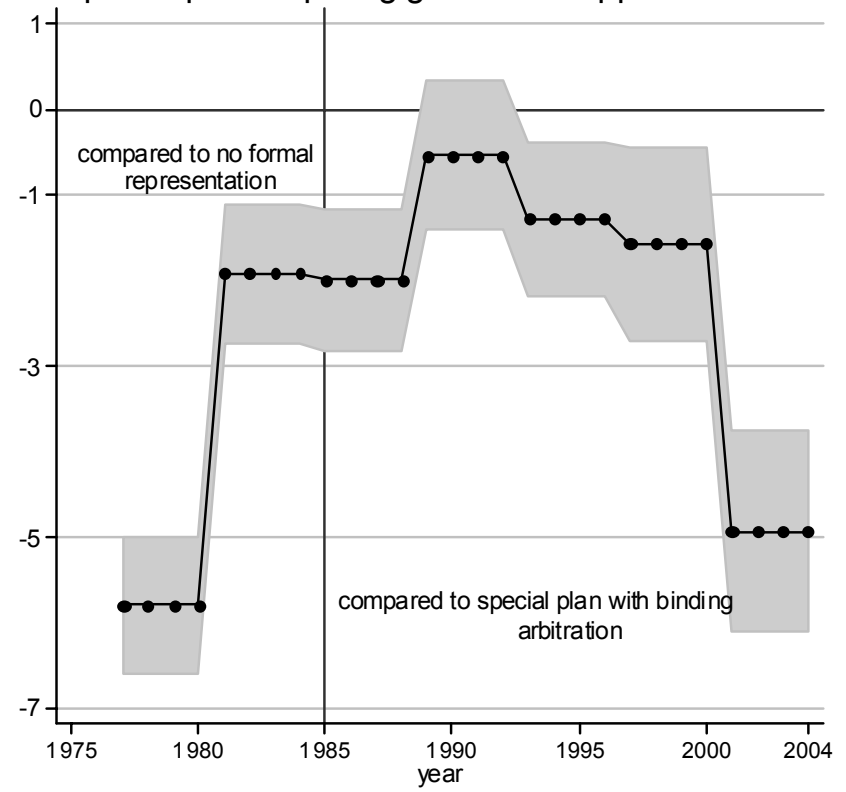


Figure 6. Average salary difference compared to next lower rank $95 \%$ confidence interval is shaded
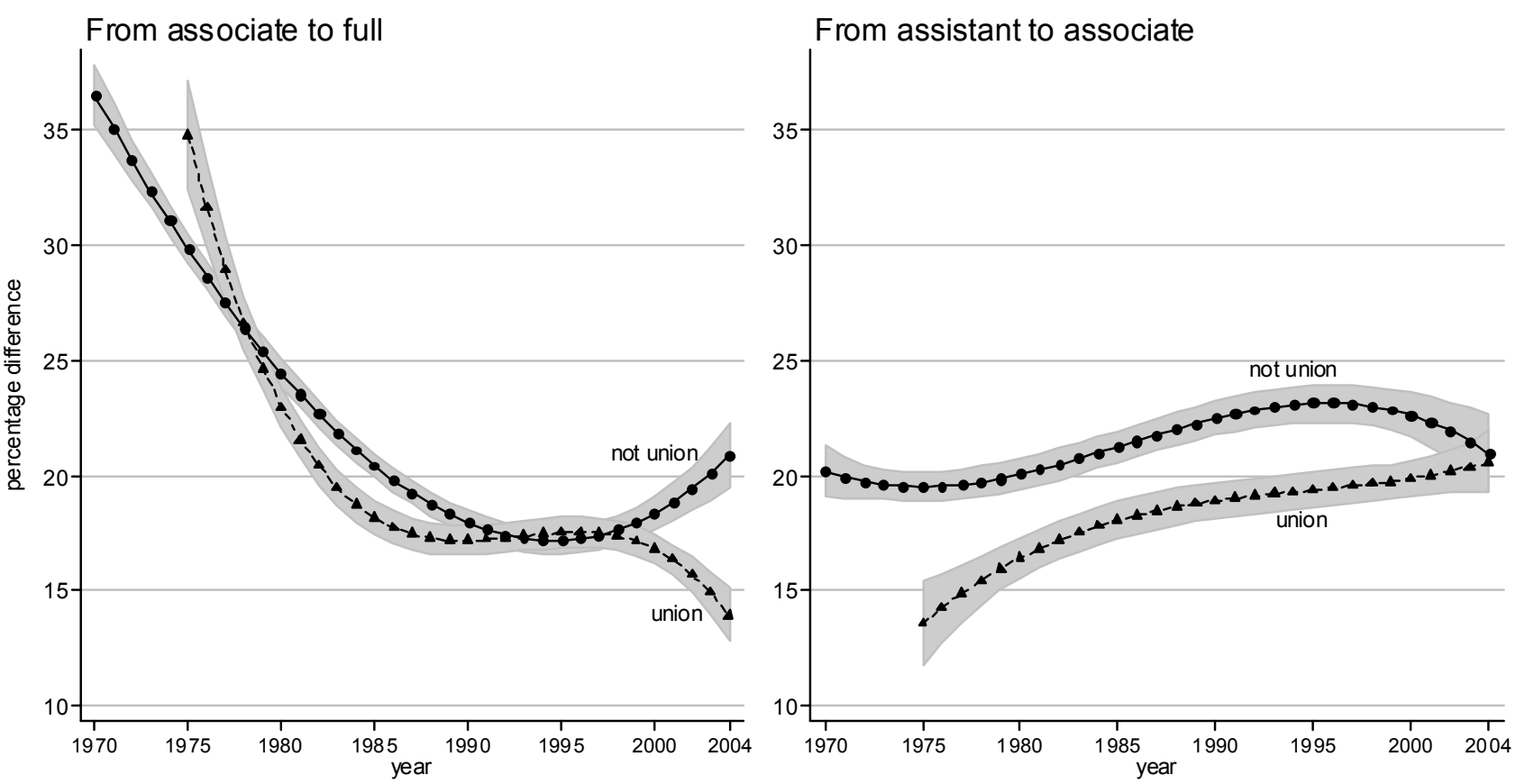

Figure 7 . Salary-age profiles, relative to the under 30 age group
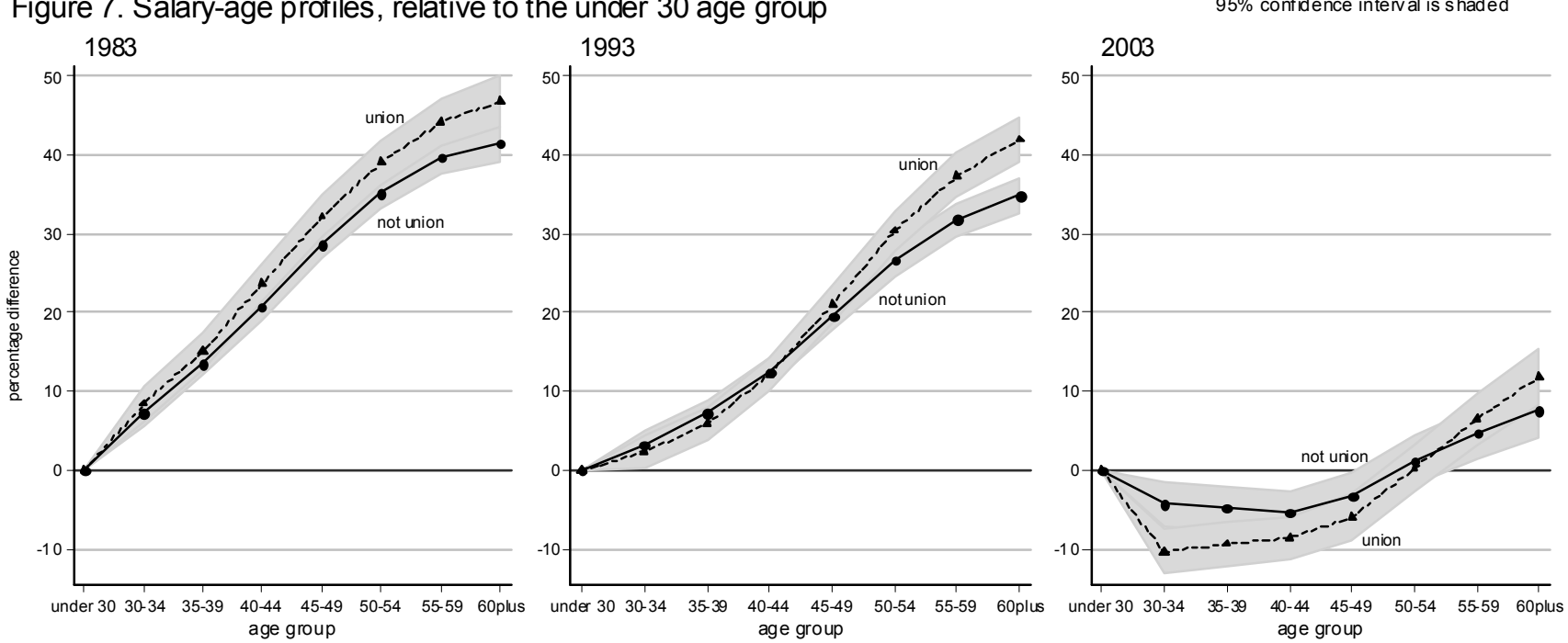
Appendix: Table A1. Regression Coefficients

\begin{tabular}{|c|c|c|c|c|c|}
\hline \multirow{3}{*}{ publications per faculty } & \multirow{3}{*}{$\begin{array}{r}\text { Base line } \\
0.0247\end{array}$} & Single dummy & \multicolumn{3}{|c|}{ university time varying age \& rank } \\
\hline & & \multicolumn{2}{|c|}{ variables specific effects } & \multirow{2}{*}{$\begin{array}{l}\text { effects } \\
0.0145\end{array}$} & \multirow{2}{*}{$\begin{array}{l}\text { effects } \\
0.0176\end{array}$} \\
\hline & & 0.0188 & -0.0009 & & \\
\hline & 15.64 & 10.71 & -0.36 & 7.66 & 10.03 \\
\hline \multirow[t]{2}{*}{ real rent } & 0.0345 & 0.0308 & 0.0323 & 0.0196 & 0.0205 \\
\hline & 17.07 & 14.39 & 14.09 & 7.04 & 7.64 \\
\hline \multirow[t]{2}{*}{ percent women faculty (\%WF) } & -0.0287 & -0.0320 & -0.0213 & -0.0348 & -0.0291 \\
\hline & -8.23 & -8.72 & -5.30 & -8.64 & -7.55 \\
\hline \multirow[t]{2}{*}{$\% \mathrm{WF} x$ trend } & 0.0266 & 0.0313 & 0.0271 & 0.0373 & 0.0284 \\
\hline & 6.25 & 6.97 & 5.75 & 7.48 & 5.97 \\
\hline \multirow[t]{2}{*}{$\% \mathrm{WF} x$ trend squared } & -0.0086 & -0.0102 & -0.0101 & -0.0133 & -0.0098 \\
\hline & -5.47 & -6.17 & -5.94 & -7.18 & -5.54 \\
\hline \multirow[t]{2}{*}{$\% W F \times$ trend cubed } & 0.0009 & 0.0011 & 0.0012 & 0.0015 & 0.0011 \\
\hline & 5.13 & 5.81 & 6.03 & 7.24 & 5.58 \\
\hline \multirow[t]{2}{*}{ full professor dummy (FPD) } & 0.5201 & 0.5155 & 0.5121 & 0.5175 & 0.4252 \\
\hline & 21.63 & 21.61 & 21.91 & 21.80 & 15.68 \\
\hline \multirow[t]{2}{*}{ FPD $x$ trend } & -0.2514 & -0.2430 & -0.2358 & -0.2457 & -0.1190 \\
\hline & -8.41 & -8.19 & -8.11 & -8.31 & -3.39 \\
\hline \multirow[t]{2}{*}{ FPD $x$ trend squared } & 0.0571 & 0.0532 & 0.0496 & 0.0542 & 0.0020 \\
\hline & 4.96 & 4.66 & 4.43 & 4.76 & 0.14 \\
\hline \multirow[t]{2}{*}{ FPD $x$ trend cubed } & -0.0042 & -0.0037 & -0.0032 & -0.0039 & 0.0029 \\
\hline & -3.05 & -2.71 & -2.38 & -2.80 & 1.70 \\
\hline \multirow[t]{2}{*}{ associate prof. dummy (APD) } & 0.2552 & 0.2500 & 0.2500 & 0.2449 & 0.2460 \\
\hline & 10.16 & 10.03 & 10.24 & 9.88 & 8.93 \\
\hline \multirow[t]{2}{*}{ APD $x$ trend } & -0.1157 & -0.1072 & -0.1035 & -0.1031 & -0.1058 \\
\hline & -3.60 & -3.36 & -3.31 & -3.25 & -2.90 \\
\hline \multirow[t]{2}{*}{ APD $x$ trend squared } & 0.0488 & 0.0453 & 0.0430 & 0.0449 & 0.0503 \\
\hline & 3.89 & 3.64 & 3.53 & 3.62 & 3.43 \\
\hline \multirow[t]{2}{*}{ APD $x$ trend cubed } & -0.0059 & -0.0055 & -0.0052 & -0.0056 & -0.0066 \\
\hline & -3.90 & -3.65 & -3.51 & -3.72 & -3.62 \\
\hline \multirow[t]{2}{*}{ age 30-34 dummy (age2DV) } & -0.0138 & -0.0137 & -0.0161 & -0.0106 & 0.0129 \\
\hline & -0.60 & -0.60 & -0.71 & -0.46 & 0.55 \\
\hline \multirow[t]{2}{*}{ age 35-39 dummy (age3DV) } & -0.0019 & -0.0031 & -0.0078 & -0.0016 & 0.0161 \\
\hline & -0.08 & -0.13 & -0.34 & -0.07 & 0.68 \\
\hline \multirow[t]{2}{*}{ age 40-44 dummy (age4DV) } & -0.0592 & -0.0617 & -0.0678 & -0.0599 & -0.0395 \\
\hline & -2.44 & -2.57 & -2.88 & -2.49 & -1.61 \\
\hline \multirow[t]{2}{*}{ age 45-49 dummy (age5DV) } & -0.1334 & -0.1368 & -0.1432 & -0.1367 & -0.1045 \\
\hline & -5.35 & -5.53 & -5.91 & -5.52 & -4.11 \\
\hline \multirow[t]{2}{*}{ age 50-54 dummy (age6DV) } & -0.1847 & -0.1898 & -0.1976 & -0.1913 & -0.1491 \\
\hline & -7.15 & -7.40 & -7.86 & -7.45 & -5.60 \\
\hline
\end{tabular}




\begin{tabular}{|c|c|c|c|c|c|}
\hline \multirow[t]{2}{*}{ age 55-59 dummy (age7DV) } & -0.2101 & -0.2156 & -0.2192 & -0.2168 & -0.1819 \\
\hline & -7.71 & -7.98 & -8.27 & -8.01 & -6.44 \\
\hline \multirow[t]{2}{*}{ age 60\&over dummy (age8DV) } & -0.2368 & -0.2429 & -0.2467 & -0.2454 & -0.2200 \\
\hline & -8.27 & -8.55 & -8.86 & -8.63 & -7.37 \\
\hline \multirow[t]{2}{*}{ age2DV $x$ trend } & 0.0990 & 0.0987 & 0.1001 & 0.0956 & 0.0684 \\
\hline & 4.47 & 4.49 & 4.65 & 4.34 & 3.04 \\
\hline \multirow[t]{2}{*}{ age3DV $\mathrm{x}$ trend } & 0.1463 & 0.1468 & 0.1496 & 0.1453 & 0.1217 \\
\hline & 6.59 & 6.67 & 6.94 & 6.57 & 5.40 \\
\hline \multirow[t]{2}{*}{ age4DV $\mathrm{x}$ trend } & 0.2452 & 0.2465 & 0.2503 & 0.2446 & 0.2170 \\
\hline & 10.86 & 11.01 & 11.41 & 10.88 & 9.37 \\
\hline \multirow[t]{2}{*}{ age5DV $\mathrm{x}$ trend } & 0.3485 & 0.3503 & 0.3546 & 0.3502 & 0.3144 \\
\hline & 15.15 & 15.35 & 15.86 & 15.28 & 13.22 \\
\hline \multirow[t]{2}{*}{ age6DV $x$ trend } & 0.4147 & 0.4175 & 0.4228 & 0.4190 & 0.3777 \\
\hline & 17.63 & 17.89 & 18.49 & 17.88 & 15.39 \\
\hline \multirow[t]{2}{*}{ age7DV $x$ trend } & 0.4494 & 0.4525 & 0.4550 & 0.4535 & 0.4213 \\
\hline & 18.54 & 18.81 & 19.31 & 18.78 & 16.58 \\
\hline \multirow[t]{2}{*}{ age8DV $x$ trend } & 0.4690 & 0.4725 & 0.4753 & 0.4744 & 0.4513 \\
\hline & 18.74 & 19.03 & 19.54 & 19.05 & 17.08 \\
\hline \multirow[t]{2}{*}{ age2DV $x$ trend squared } & -0.0263 & -0.0262 & -0.0264 & -0.0256 & -0.0189 \\
\hline & -5.94 & -5.96 & -6.13 & -5.83 & -4.21 \\
\hline \multirow[t]{2}{*}{ age3DV $x$ trend squared } & -0.0380 & -0.0380 & -0.0384 & -0.0377 & -0.0319 \\
\hline & -8.60 & -8.67 & -8.94 & -8.59 & -7.13 \\
\hline \multirow[t]{2}{*}{ age4DV $x$ trend squared } & -0.0578 & -0.0580 & -0.0585 & -0.0575 & -0.0513 \\
\hline & -12.92 & -13.04 & -13.44 & -12.93 & -11.21 \\
\hline \multirow[t]{2}{*}{ age5DV $x$ trend squared } & -0.0763 & -0.0764 & -0.0770 & -0.0763 & -0.0693 \\
\hline & -16.78 & -16.94 & -17.44 & -16.90 & -14.77 \\
\hline \multirow[t]{2}{*}{ age6DV $x$ trend squared } & -0.0857 & -0.0860 & -0.0868 & -0.0861 & -0.0791 \\
\hline & -18.54 & -18.75 & -19.32 & -18.76 & -16.43 \\
\hline \multirow[t]{2}{*}{ age7DV $x$ trend squared } & -0.0897 & -0.0900 & -0.0904 & -0.0901 & -0.0856 \\
\hline & -19.01 & -19.23 & -19.71 & -19.22 & -17.34 \\
\hline \multirow[t]{2}{*}{ age8DV $x$ trend squared } & -0.0906 & -0.0910 & -0.0915 & -0.0912 & -0.0891 \\
\hline & -18.77 & -19.01 & -19.50 & -19.02 & -17.49 \\
\hline \multirow[t]{2}{*}{ constant } & 10.6642 & 10.6845 & 10.6108 & 10.7557 & 10.7554 \\
\hline & 610.71 & 594.44 & 517.56 & 506.52 & 521.21 \\
\hline \multirow[t]{2}{*}{ union dummy variable } & & -0.0027 & & & 0.0055 \\
\hline & & -1.12 & & & 0.53 \\
\hline \multirow[t]{2}{*}{ SPRGA dummy variable } & & -0.0169 & & & -0.0181 \\
\hline & & -7.08 & & & -7.25 \\
\hline \multirow[t]{2}{*}{ SPBA dummy variable } & & 0.0125 & & & 0.0111 \\
\hline & & 3.98 & & & 3.28 \\
\hline \multirow[t]{2}{*}{ union dummy 1975-1979 } & & & & -0.0036 & \\
\hline & & & & -1.06 & \\
\hline union dummy 1980-1984 & & & & -0.0061 & \\
\hline
\end{tabular}




\begin{tabular}{|c|c|c|}
\hline & -1.74 & \\
\hline \multirow[t]{2}{*}{ union dummy 1985-1988 } & -0.0137 & \\
\hline & -3.41 & \\
\hline \multirow[t]{2}{*}{ union dummy 1989-1992 } & -0.0048 & \\
\hline & -1.16 & \\
\hline \multirow[t]{2}{*}{ union dummy 1993-1996 } & -0.0050 & \\
\hline & -1.10 & \\
\hline \multirow[t]{2}{*}{ union dummy 1997-2000 } & -0.0199 & \\
\hline & -3.98 & \\
\hline \multirow[t]{2}{*}{ union dummy 2001-2004 } & -0.0456 & \\
\hline & -8.32 & \\
\hline \multirow[t]{2}{*}{ SPRGA dummy 1977-1980 } & -0.0597 & \\
\hline & -13.64 & \\
\hline \multirow[t]{2}{*}{ SPRGA dummy 1981-1984 } & -0.0195 & \\
\hline & -4.60 & \\
\hline \multirow[t]{2}{*}{ SPRGA dummy 1985-1988 } & -0.0201 & \\
\hline & -4.65 & \\
\hline \multirow[t]{2}{*}{ SPRGA dummy 1989-1992 } & -0.0054 & \\
\hline & -1.22 & \\
\hline \multirow[t]{2}{*}{ SPRGA dummy 1993-1996 } & -0.0129 & \\
\hline & -2.79 & \\
\hline \multirow[t]{2}{*}{ SPRGA dummy 1997-2000 } & -0.0159 & \\
\hline & -2.68 & \\
\hline \multirow[t]{2}{*}{ SPRGA dummy 2001-2004 } & -0.0506 & \\
\hline & -7.98 & \\
\hline \multirow[t]{2}{*}{ union dummy $x$ full prof dum (FPD) } & & 0.6590 \\
\hline & & 7.01 \\
\hline \multirow[t]{2}{*}{ union dummy $x$ FPD $x$ trend } & & -0.7416 \\
\hline & & -7.28 \\
\hline \multirow[t]{2}{*}{ union dummy $x$ FPD $x$ trend sqrd } & & 0.2628 \\
\hline & & 7.42 \\
\hline \multirow[t]{2}{*}{ union dummy $x$ FPD $x$ trend cubed } & & -0.0298 \\
\hline & & -7.55 \\
\hline \multirow[t]{2}{*}{ union dummy $x$ assoc dum (APD) } & & -0.2934 \\
\hline & & -3.92 \\
\hline \multirow[t]{2}{*}{ union dummy $x$ APD $x$ trend } & & 0.2870 \\
\hline & & 3.59 \\
\hline \multirow[t]{2}{*}{ union dummy $x$ APD $x$ trend sqrd } & & -0.1009 \\
\hline & & -3.64 \\
\hline \multirow[t]{2}{*}{ union dummy $x$ APD $x$ trend cubed } & & 0.0115 \\
\hline & & 3.69 \\
\hline \multirow[t]{2}{*}{ union dummy $x$ age2DV } & & -0.0847 \\
\hline & & -2.07 \\
\hline \multirow[t]{2}{*}{ union dummy $x$ age3DV } & & 0.0479 \\
\hline & & 1.29 \\
\hline union dummy $x$ age4DV & & 0.0708 \\
\hline
\end{tabular}




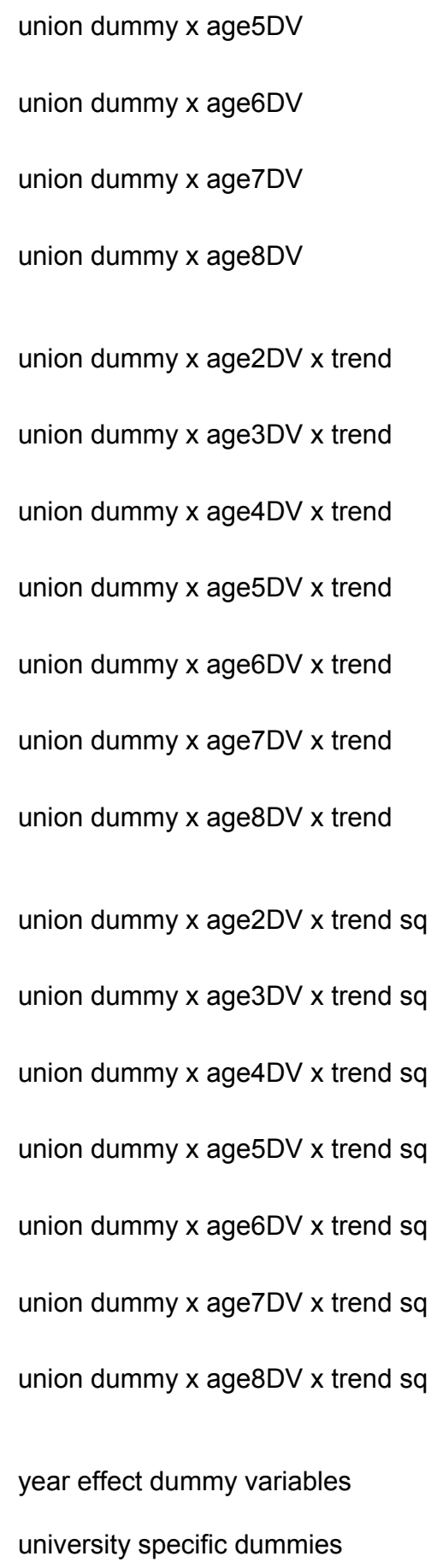

